\title{
Identificación de restos de tejidos humanos en instrumentos rituales prehispánicos de México
}

Identification of Human Tissue Remains on Mexican Pre-Hispanic Ritual Instruments

\section{Luisa Mainou Cervantes}

Coordinación Nacional de Conservación del Patrimonio Cultural (CNCPC), Instituto Nacional de Antropología e Historia (INAH), México gatomainou@hotmail.com

\section{Silvia Antuna Bizarro}

Departamento de Biología Celular y Tisular

Facultad de Medicina,

Universidad Nacional Autónoma de México (UNAM), México

silpolla@hotmail.com

\section{Teresa Fortoul Van der Goes}

Departamento de Biología Celular y Tisular,

Facultad de Medicina,

Universidad Nacional Autónoma de México (UNAM), México

fortoul@unam.mx

\section{Luisa Straulino Mainou}

Coordinación Nacional de Conservación del Patrimonio Cultural (CNCPC) Instituto Nacional de Antropología e Historia (INAH), México azucarylimon@gmail.com

\section{Resumen}

Esta INVESTIGACIÓN se enfocó a siete instrumentos rituales, cuya tipología formal se ha relacionado con actividades de sacrificio y autosacrificio en diversas culturas prehispánicas de lo que hoy es México. Su finalidad fue encontrar restos orgánicos humanos que los relacionaran con las funciones ya señaladas. Para ello, se inició con la obtención de muestras de cuatro elementos elaborados con obsidiana, de una punta de maguey y de dos punzones tallados en hueso, las cuales se sometieron a análisis por microscopia electrónica de barrido (MEB). Un equipo interdisciplinario de profesionales de la restauración y la medicina interpretó los resultados, quienes concluyeron la identificación de diversos restos orgánicos diagnósticos, tales como células sanguíneas y restos tisulares humanos.

Palabras clave

instrumentos prehispánicos; sacrificio; autosacrificio; restos orgánicos; microscopia electrónica de barrido (MEB); México

\section{Abstract}

This RESEARCH focuses on seven ritual instruments, whose formal typology has been liked with sacrifice and self-sacrifice in different pre-Hispanic cultures of today Mexico. Its purpose was to find 
organic human remains that would link the artefacts with the abovementioned practices. The study began by obtaining samples from four elements made of obsidian, a maguey spike, and two tip points carved out of bone, all which were subjected to scanning electronic microscopy (SEM). Finally, an interdisciplinary team of restoration and medicine professionals interpreted the results, which concluded with the identification of diverse organic diagnostics remains, such as blood cells and human tissue remains.

\section{Keywords}

pre-Columbian instruments; sacrifice; self-sacrifice; organic remains; scanning electron microscopy (SEM); Mexico

\section{Introducción}

E I sacrificio y el autosacrificio en la época prehispánica de la región que se considera Mesoamérica se ha estudiado y debatido ampliamente en diversas publicaciones (cfr. Boone 1984; González 1985; Nájera 1987; Ibarra García 2001; Graulich 2005; López Luján y Olivier 2010; Tiesler y Cucina 2010; Henderson 2012), que coinciden con la idea de que la mayoría de la información que se tiene acerca de estas prácticas se basa en fuentes iconográficas, artísticas e históricas, de modo que en el proceso de comprenderlas poco se ha tomado en cuenta el registro arqueológico. Más aún: sólo excepcionalmente se consideran los datos tafonómicos (cfr. Kron 2006; Tiesler y Cucina 2010; López Austin y López Luján 2010; Ribeiro Marques 2013), y todavía son más reducidos los estudios realizados para localizar residuos arqueológicos directamente en objetos de tipologías formales asociadas con prácticas de sacrificio y autosacrificiales que se elaboraron en obsidiana, pedernal, hueso, puntas de maguey, puntas de raya, entre otros (Loy 1993; Jones 2009; Barnard y Eerkens 2007; Malainey 2011).

Es de destacar que la recuperación de residuos arqueológicos que ayuden a comprobar el uso de artefactos en actividades de sacrificio o autosacrificio es de gran importancia para la investigación arqueológica, ya que los grados de inferencia que se alcanzan se objetivizan en la materialidad involucrada en el desarrollo de estas prácticas culturales en la antigüedad mesoamericana (Loy 1993; Jones 2009; Barnard y Eerkens 2007; Malainey 2011). Ahora bien, la mayoría de los análisis al respecto se han limitado a identificar restos de sangre humana en los objetos; de hecho, desde los años ochenta del siglo XX se han empleado para ello diversas técnicas analíticas, incluida la microscopia óptica (MO) con luz transmitida, así como pruebas químicas e inmunológicas (Loy y Hardy 1992; Loy 1983, 1987, 1993; Leach y Mauldin 1995; Eisele et al. 1995; Jones 2009; Allen et al. 1995). En "Survival and detection of blood residues on stone tools" (Eisele et al. 1995) se publicaron, además de un compendio de los análisis que claman haber tenido éxito en la identificación de sangre en contextos arqueológicos, una re- copilación de trabajos y explicaciones que exponen los problemas que pueden llevar a que dichos análisis den falsos positivos, o bien, que sean aptos para tal propósito. En lo particular, existe un debate sobre si los análisis inmunológicos en sangre conducen a resultados certeros cuando las proteínas de la sangre ya están degradadas, tal y como sucede con las muestras arqueológicas (cfr. Kooyman et al. 2001; Eisele et al. 1995; Dier 2011; Brown y Brown 2011). Paradójicamente, aunque la microscopia electrónica de barrido (MEB: scanning electron microscopy [SEM]) es una técnica probada para la identificación micromorfológica de vestigios de materia orgánica en la superficie de objetos, poco se ha explorado en la identificación de residuos orgánicos en artefactos arqueológicos.

En este estudio, en cambio, se ha decidido explorar la potencialidad de la MEB, y se han utilizado para ello los principios de la hemotafonomía propuestos por Policarp Hortolà (1992, 2002, 2004); específicamente, aquí se dan a conocer los resultados del análisis mediante MEB llevado a cabo en siete instrumentos prehispánicos de tipologías formales asociadas con prácticas de sacrificio y autosacrificio que, procedentes de diversos sitios arqueológicos de México, nos permitieron detectar en su superficie la presencia de tejidos y células sanguíneas. Con base en lo anterior, la investigación aporta datos científicos conclusivos que señalan positivamente el uso de estos artefactos como instrumentos de autosacrificio y sacrificio humanos, información que complementa la proporcionada por otras fuentes historiográficas, iconográficas y arqueológicas.

\section{Casos de estudio}

Esta INVESTIGACIÓN se centró en el estudio de siete artefactos prehispánicos: cuatro instrumentos de sacrificio elaborados con obsidiana y tres de autosacrificio, dos hechos con hueso, y el otro, con una espina o punta de maguey. Los datos arqueológicos y características se indican a continuación.

\section{Dos cuchillos de obsidiana}

El arqueólogo Luis Morett descubrió en 1992 dos cuchiIlos de obsidiana (Figura 1), de aproximadamente $15 \mathrm{~cm}$ de largo, dentro de sendas cavidades orales de individuos hallados en contexto arqueológico funerario múltiple en el rancho El Zethé, Hidalgo, como parte de una ofrenda de cuchillos de ese material; más una vasija zoomorfa con la imagen de un murciélago, todos ellos depositados dentro de una cista ubicada en una subestructura con muros de adobe y cimentaciones de toba volcánica datadas para el siglo VIII d. C. (Mainou et al. 1994). Las osamentas presentaban evidencias de desmembramiento, mientras que los cuchillos, pequeñas agrupaciones café rojizas en las fracturas concoideas de la obsidiana, así 

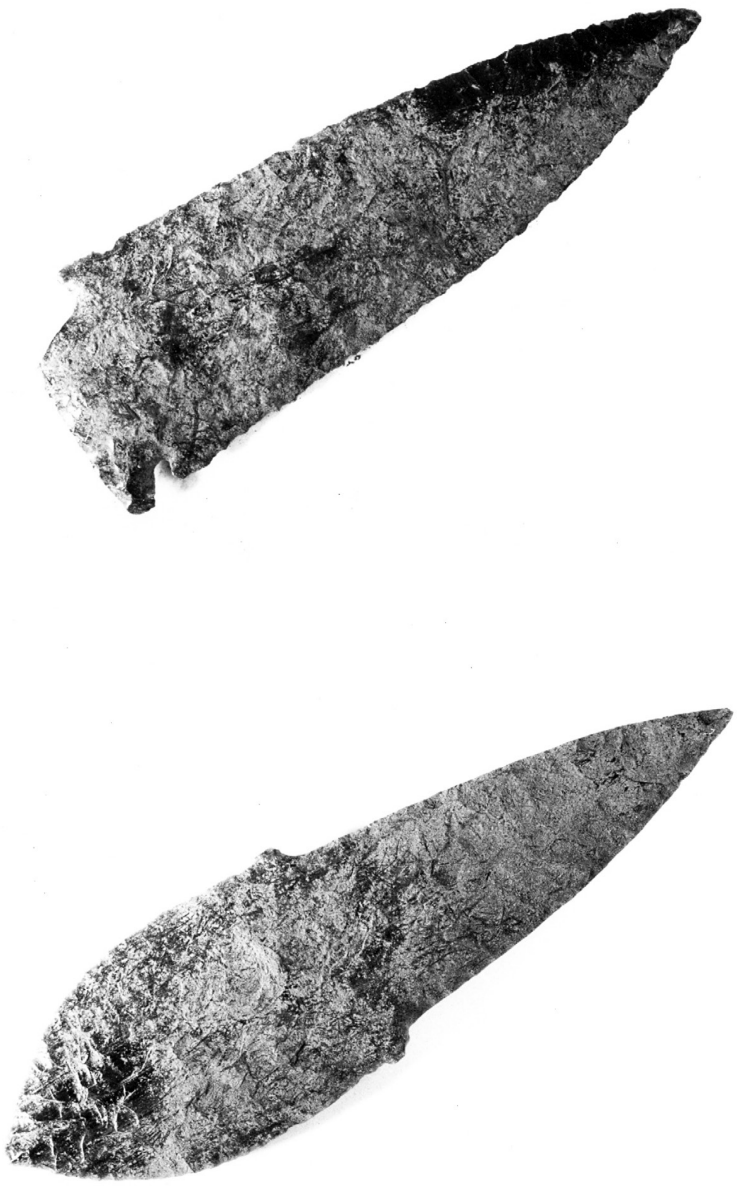

FIGURA 1. Cuchillos bifaciales de obsidiana, Zethé, Hidalgo (Fotografías: Ricardo Castro, 1994; cortesía: CNCPC-INAH).

como minúsculas fibrillas blanquecinas en sus filos (Mainou et al. 1994).

\section{Dos tranchets}

En el 2003 se realizó una excavación arqueológica al interior del centro cívico-religioso más importante del sitio arqueológico de Cantona, Puebla-Tlaxcala, donde se localizó una rica ofrenda de instrumentos de sacrificio hechos con obsidiana; entre ellos destacan navajas prismáticas, navajas de cresta, raspadores, cuchillos sacrificiales y tranchets, o cortadores (Martínez Callejas en prensa). Aunque nuestro estudio analizó treinta y un instrumentos de esta ofrenda, para este artículo únicamente se reportarán los resultados de dos de ellos (Figura 2), los cuales se distinguieron por presentar la mayor abundancia de fibras cortas de color amarillento en su parte distal, pequeños fragmentos de tejido color blanquecino fuertemente adherido a la superficie y cúmulos, también pequeños, de color café rojizo en sus fracturas concoideas.
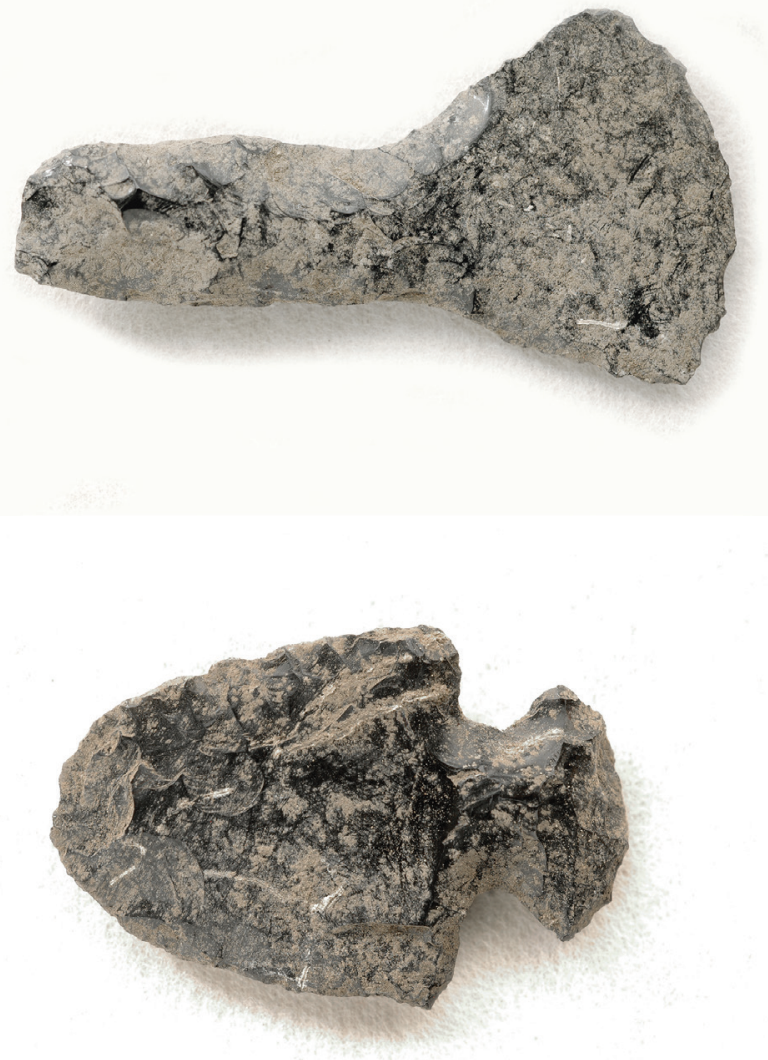

FIGURA 2. Tranchets bifaciales de obsidiana: 2a. Tranchet 27, 2b. Tranchet 28 Cantona, Puebla (Fotografías: Ricardo Castro, 2011; cortesía: CNCPC-INAH).

Una punta de maguey

Este espécimen (Figura 3) se rescató en octubre del 2007 durante las exploraciones arqueológicas realizadas por la Subdirección de Arqueología Subacuática (SAS) del Instituto Nacional de Antropología e Historia (INAH) en las lagunas del Nevado de Toluca (Junco 2010). Formó parte de una rica ofrenda del Posclásico Tardío (1200/13001521 d. C.) consistente en bastones de mando hechos con madera, puntas de maguey y figuras de copal, piezas que se sometieron a un proceso integral de conservación, investigación y divulgación (Mainou 2009).

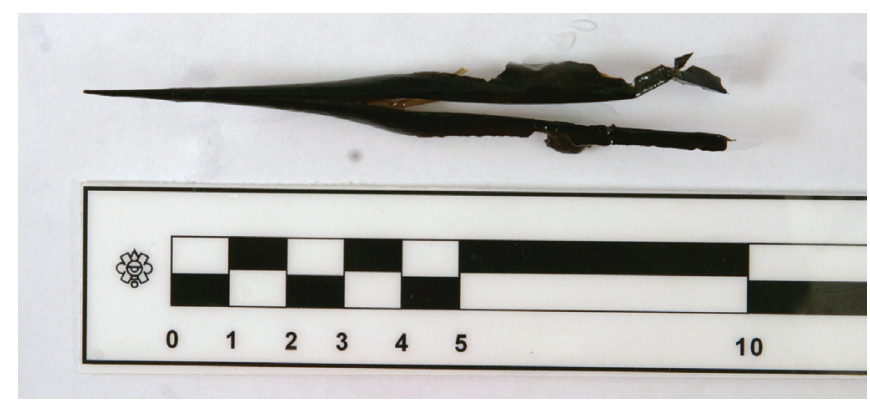

FIGURA 3. Punta de maguey utilizada en autosacrificio, Nevado de Toluca, Estado de México (Fotografía: Ricardo Castro, 2009; cortesía: CNCPC-INAH). 
Dos punzones de hueso

El arqueólogo Roberto García Moll halló los punzones de hueso de animal aquí analizados junto con otros seis objetos pertenecientes a la reina maya Ix K'abal Xook en la tumba 2 de la estructura 23 del sitio arqueológico de Yaxchilán, Chiapas (Stuart 2013). Su forma es alargada (10 $\mathrm{cm}$ de longitud), de sección circular en la parte proximal y ojival, porción distal en punta y sin remate (Figura 4). En la parte media contienen inscripciones de glifos mayas coloreadas con cinabrio que, de acuerdo con Stuart (2013), rezan:

Hueso 1. u baakel bahlam Ix K'abal Xook / Aj K'ahk' O' Chahk - Su hueso de jaguar de Ix K'abal Xook/ Aj K'ahk' O'Chahk (nombre del dios en la parte superior).

Hueso 2. took'al ajaw u mayij baak Ix K'abal Xook -El señor Pedernal es el hueso de ofrenda de Ix K'abal Xook.
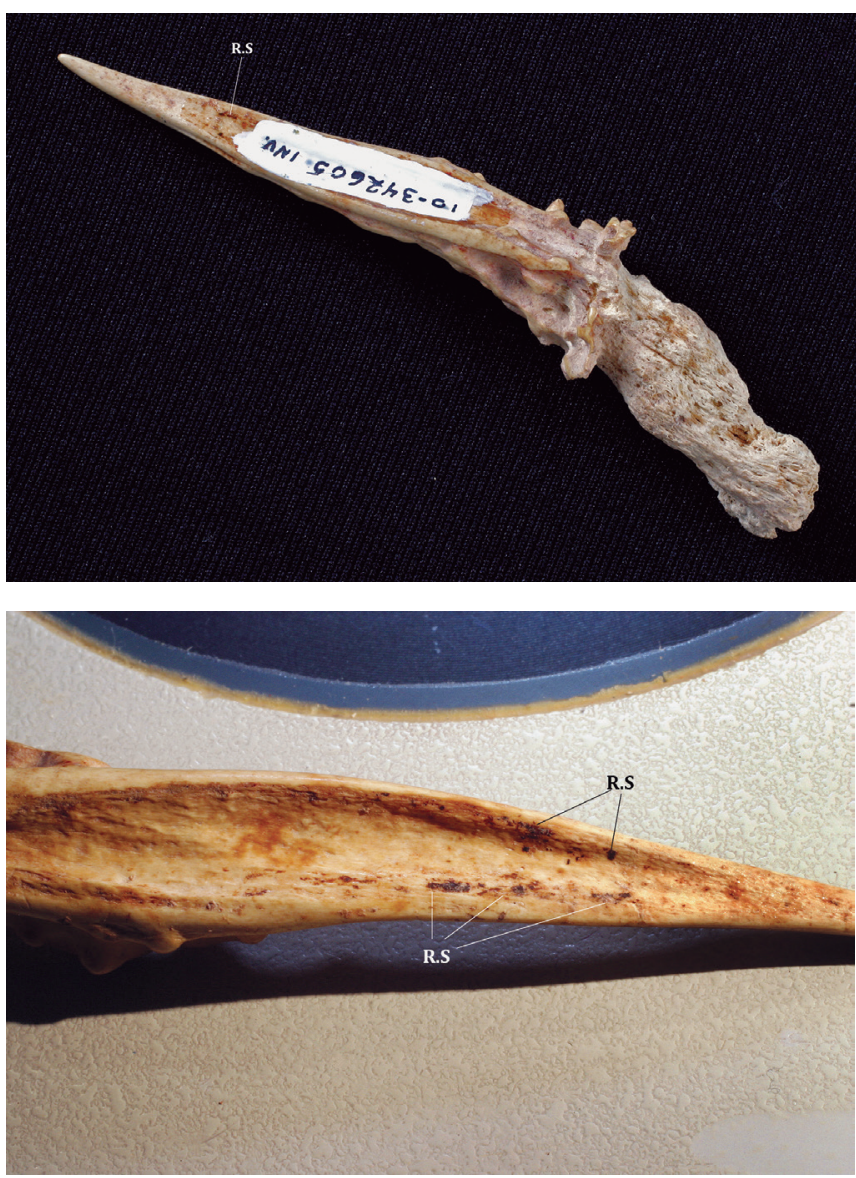

FIGURA 4. Punzones de hueso para autosacrificio, Yaxchilán, Chiapas; Restos sanguíneos (R.S) bien conservados sobre la superficie del hueso (Fotografías: Ricardo Castro, 2004; cortesía: CNCPC-INAH).

\section{Desarrollo}

A simple vista y con la ayuda de un microscopio estereoscópico Nikon SMZ800 ${ }^{\circledR}$ se detectaron en todos los artefactos en estudio pequeñas acumulaciones de color café rojizas, resecas y semejantes a costras, y/o microfibrillas. Con la ayuda del mismo microscopio se obtuvieron muestras de estos sustratos por raspado y separado con bisturí; además, de cada cuchillo de obsidiana se consiguió una microlasca. Las muestras se montaron en cintas de carbón y se limpiaron con ultrasonido. Una vez limpias, se ionizaron con oro en un Fine Coat lon Sputter JEOL JFC-1100 ${ }^{\circledR}$, y después se observaron con diversos microscopios electrónicos de barrido, cuyos modelos, así como sus características de trabajo y qué muestras se observaron en cada uno, se presentan en la Figura 5.

\begin{tabular}{|c|c|c|c|}
\hline Material & Microscopio & Kilovolts & $\begin{array}{c}\text { Distancia } \\
\text { de trabajo }\end{array}$ \\
\hline Punzón de hueso & JEOL JSM-35CF $^{\circledR}$ & $15 \mathrm{kv}$ & $15 \mathrm{~mm}$ \\
\hline Punta de maguey & Zeiss DSM950 & $20 \mathrm{kv}$ & $13 \mathrm{~mm}$ \\
\hline \multirow{2}{*}{ Tranchets } & Zeiss DSM950 & $15 \mathrm{kv}$ & $23 \mathrm{~mm}$ \\
& JEOL JSM6360LV & $25 \mathrm{kv}$ & $15 \mathrm{~mm}$ \\
& JEOL JSM6460LV $^{\circledR}$ & $20 \mathrm{kv}$ & $10 \mathrm{~mm}$ \\
\hline Cuchillos & JEOL JSM-35CF $^{\circledR}$ & $10 \mathrm{kv}$ & $15 \mathrm{~mm}$ \\
\hline
\end{tabular}

FIGURA 5. Microscopios electrónicos de barrido, modelos y características empleadas en la observación de los materiales (Tabla: autoras, 2016).

\section{Resultados}

En todas las muestras extraídas de los instrumentos en estudio estuvieron presentes múltiples estructuras con forma discal bicóncavas, cuyas dimensiones oscilan entre las 7 y las $10 \mu$ de diámetro. En algunas de ellas aún se conserva la textura aterciopelada en la superficie, mientras que en otras - por ejemplo, las de los tranchets- estas células tienen una apariencia bastante mineralizada, sin que por ello hayan perdido su característica principal: la biconcavidad.

Particularmente, en las muestras obtenidas de la puntas de maguey recuperada en las lagunas del Nevado de Toluca, las estructuras bicóncavas están cubiertas por una película delgada, posiblemente plasma que, junto con las células sanguíneas, se preservó debido a la baja temperatura del agua y a los bajos niveles de oxígeno.

En los instrumentos utilizados para corte: cuchillos y tranchets, se encontraron restos de tejido blando, entre ellos, largas fibras, cuya morfología sugiere correspondencia con tejido muscular liso. Igualmente, se observa- 
ron restos de colágena tipo $1^{1} \mathrm{y}$ algunas estructuras alargadas que morfológicamente concuerdan con estructuras propias del pelo humano.

Las muestras procedentes de los cuchillos sacrificiales de obsidiana encontrados en el rancho El Zethé, Hidalgo, presentaron en su cara anterior, en la zona más distal, minúsculas partículas café rojizo oscuro conglomeradas que estaban albergadas en las fracturas concoideas del filo, las cuales Ilamaron la atención; de la misma manera, muy adheridas a la superficie del filo de estas piezas, se detectaron pequeñas y delgadísimas fibrillas color blanquecino.

Por otro lado, se notaron, adheridos a estas estructuras cilíndricas de superficie irregular de tipo muscular, múltiples discos bicóncavos (Figura 6). En un acercamiento (Figura 7), es notable un conjunto de discos bicóncavos de 8 a $10 \mu$ de diámetro aproximadamente, con una textura aterciopelada, cuyas características morfológicas dan a entender que se trata de eritrocitos. Además, se observaron estructuras fibrosas en diferentes direcciones, de superficie irregular, con residuos de material inorgánico propios del entierro (Figura 8).

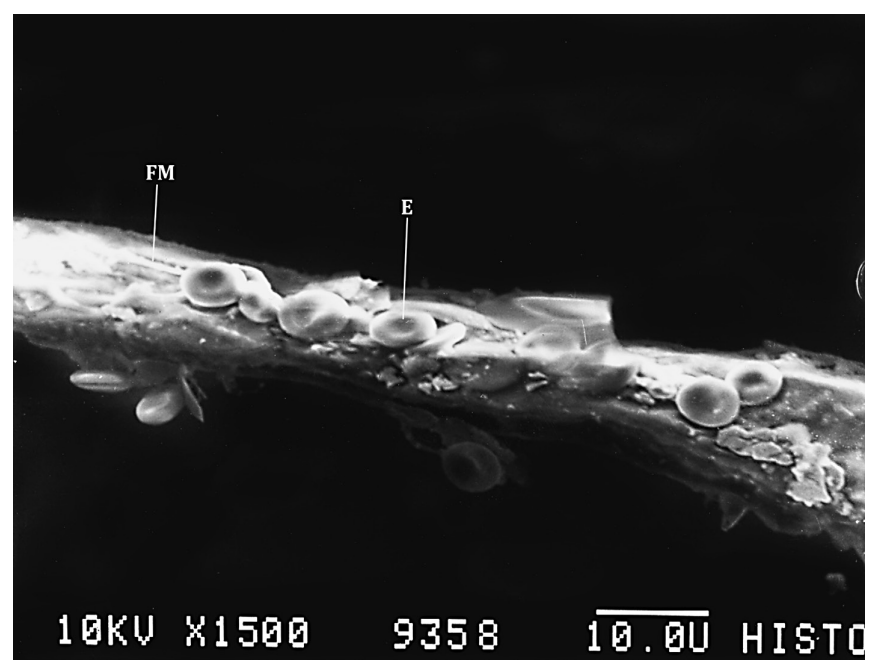

FIGURA 6. Eritrocitos (E) adheridos a fibra muscular (FM) (Fotografía: Silvia Antuna y Luisa Mainou, 1994).

En la Figura 2 se muestran dos de los treinta instrumentos de sacrificio hechos con obsidiana recuperados del sitio arqueológico de Cantona, Puebla-Tlaxcala. Se trata de los tranchets 27 y 28, pequeñas piezas que miden $4.0 \mathrm{~cm}$ de largo por $3.0 \mathrm{~cm}$ de ancho por $0.90 \mathrm{~cm}$ de espesor. En

\footnotetext{
1 Se han descrito más de 27 tipos de colágena, según sea la secuencia de aminoácidos de las cadenas polipeptídicas que las componen. La mayor parte de estos tipos de colágena se caracterizan por su organización en forma de haces. Los distintos tipos de colágena se localizan en regiones específicas de los tejidos, en las que se desempeñan funciones diversas. La colágena tipo I es la más frecuente; forma fibras gruesas y se encuentra en tejido conectivo, hueso, dentina y cemento de los dientes. (Sepúlveda 2014:58-59).
}

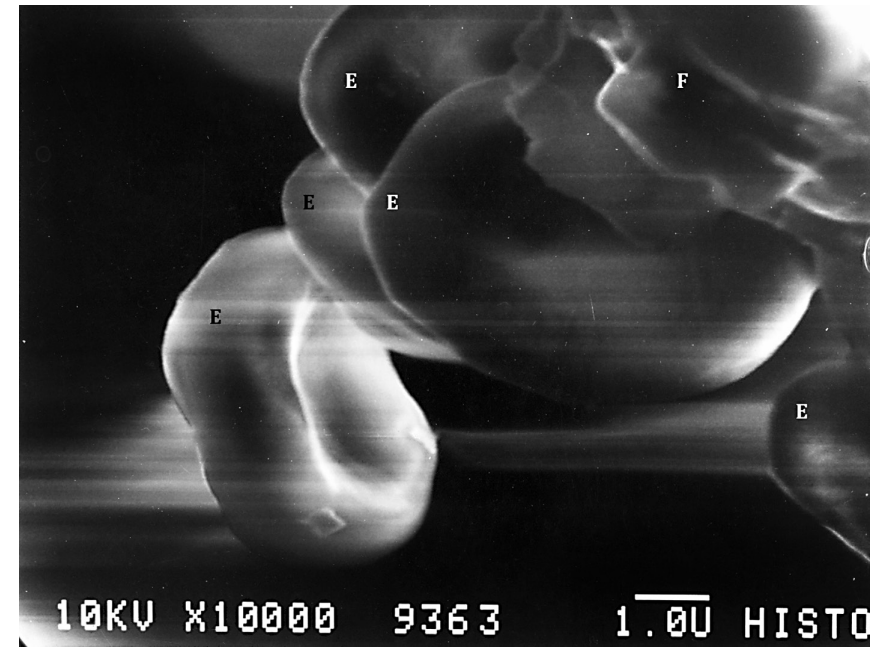

FIGURA 7. Conjunto de eritrocitos (E), agrupados y sostenidos por restos de fibrina (F). Obsérvense las características propias de estas células sanguíneas: células de 8 a 10 micras, bicóncavas y de aspecto aterciopelado (Fotografía: Silvia Antuna y Luisa Mainou, 1994).

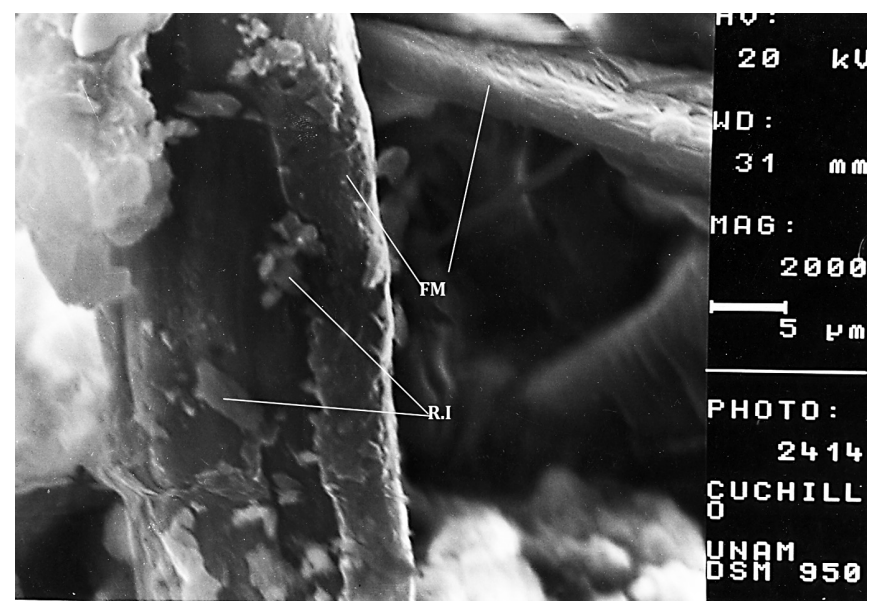

FIGURA 8. Fibra muscular (FM) con residuos de restos inorgánicos (R.I) propios de la matriz del suelo (Fotografía: Silvia Antuna y Luisa Mainou, 1994).

las Figuras 9 y 10 se aprecian restos orgánicos diversos: en la Figura 9 se observa una larga y fina fibra de colágenas sosteniendo un eritrocito, mientras que en la Figura 10 se advierte un conjunto de células discales y restos de fibrina que forman un coágulo que pende de la orilla del filo del tranchet. En la Figura 11 se aprecia un fragmento de piel; en todas las muestras analizadas, la escasez de poros lleva a pensar que se trata de restos de piel humana. La Figura 12 muestra restos de fibras musculares que, por su morfología, cabe suponer que se trata de restos de músculo liso. Por último, en la Figura 13 se presenta un conjunto de fibras de colágena tipo 1.

En las muestras obtenidas de la punta de maguey y los punzones de hueso se encontraron células sanguíneas. En la primera no se pudieron observar a simple vista tales restos, ya que las puntas son de un color muy similar a la sangre seca, caso contrario al de los punzones de sacrifi- 


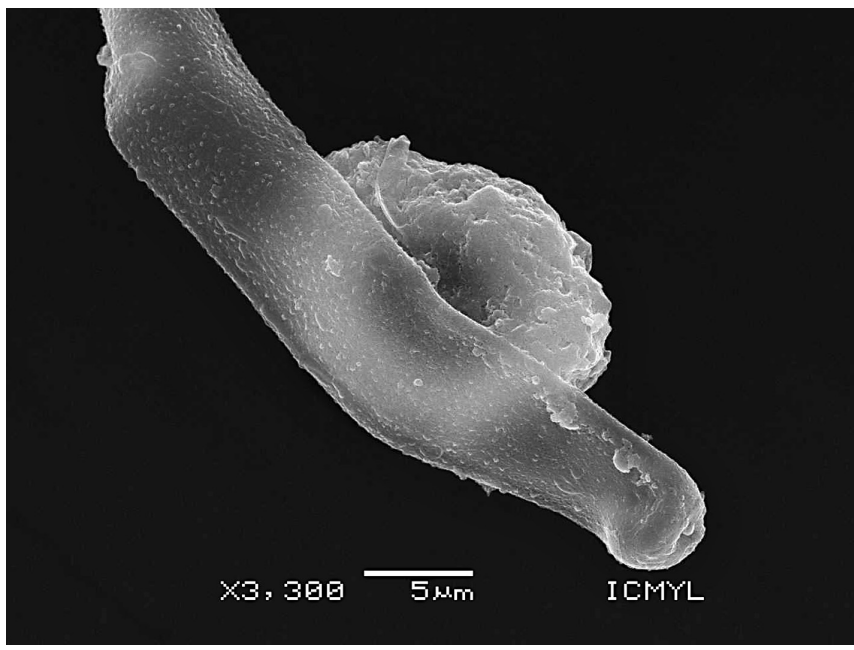

FIGURA 9. Fibras de colágena tipo 1 (Fotografía: Silvia Antuna y Luisa Mainou, 2011).

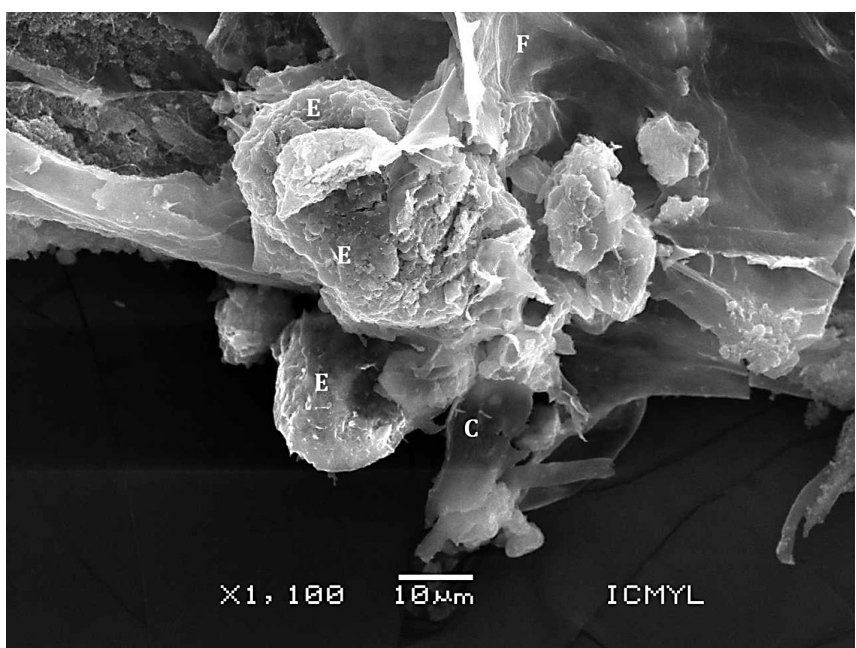

FIGURA 10. Coágulo sanguíneo formado por cuatro eritrocitos (E). También se aprecia en la imagen restos de fibrina (F) alrededor de las células sanguíneas y restos de colágena (C) (Fotografía: Silvia Antuna y Luisa Mainou, 2011).

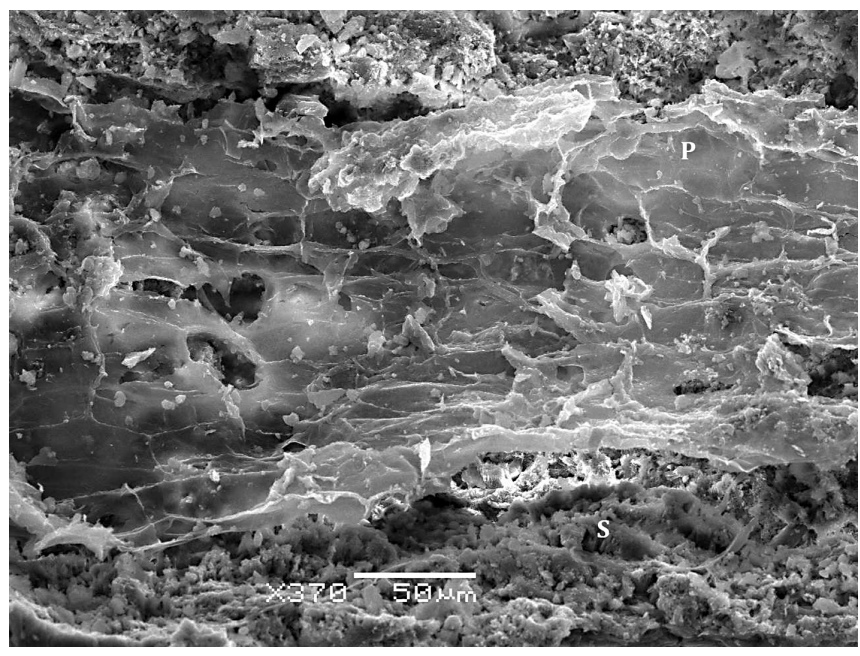

FIGURA 11. Fragmento de piel (P) sobre sustrato arqueológico (Fotografía: Silvia Antuna y Luisa Mainou, 2011).

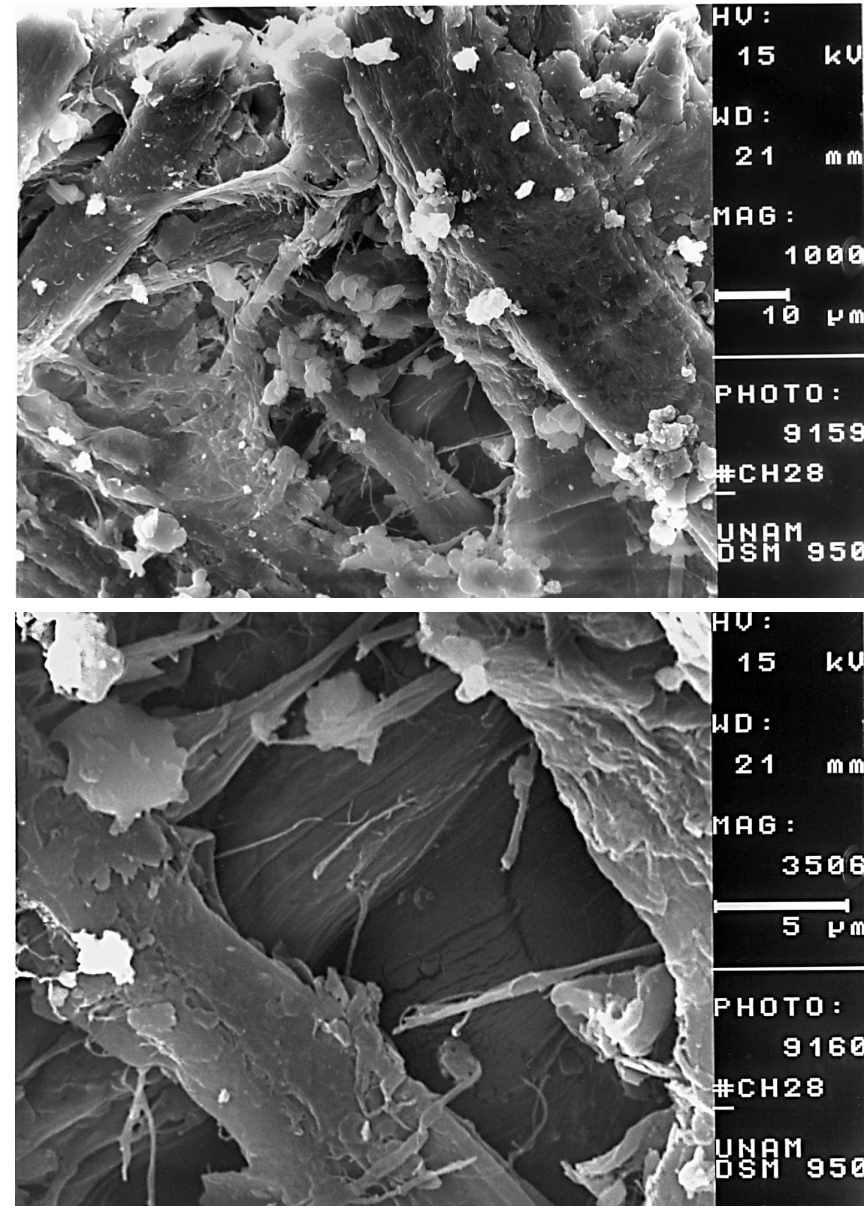

FIGURA 12. Restos de tejido muscular (Fotografías: Silvia Antuna y Luisa Mainou, 2011).

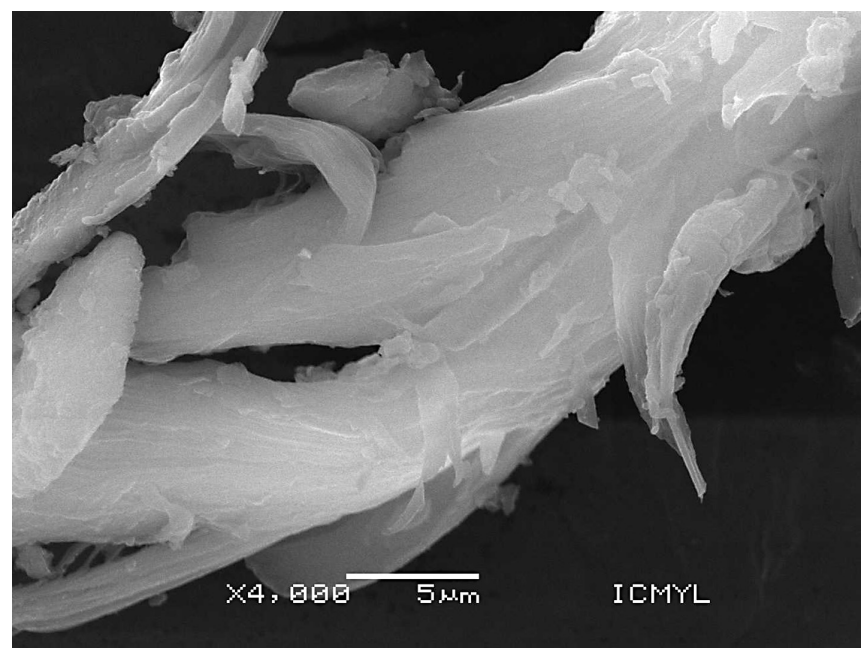

FIGURA 13. Fibras de colágena tipo 1 (Fotografía: Silvia Antuna y Luisa Mainou, 2011).

cio de Yaxchilán, donde se hallaron pequeñas costras microfracturadas de color café oscuro (Figura 4).

En la figura 3 se muestra una punta de maguey, cuyas características morfológicas y estructurales no se alteraron a pesar de haber estado bajo el agua durante más de 600 años. Una serie de discos bicóncavos de 7 a $8 \mu$ de diáme- 
tro recorre, a lo largo, este instrumento, en el que además se adhirieron restos de tejido plasmático que no pertenecen a ella (Figura 14).

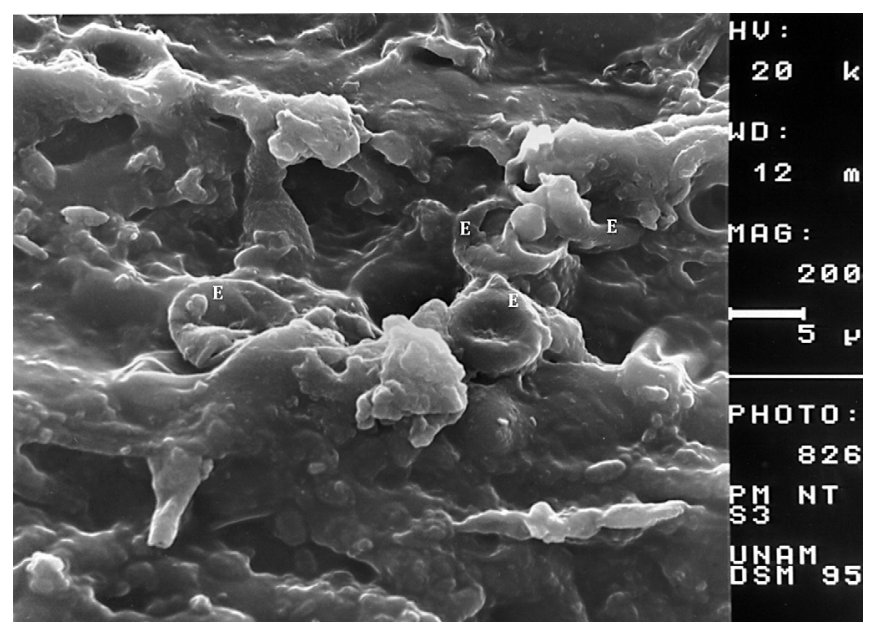

FIGURA 14. Células sanguíneas caracterizadas como eritrocitos (E) adheridos a la superficie de la púa de maguey (Fotografía: Silvia Antuna y Luisa Mainou, 2009).

En el lado posterior de la parte distal de los punzones de hueso se descubrieron áreas café rojizas que, según las observaciones, corresponden a células sanguíneas bien conservadas (Figura 4). En el MEB se reconocieron varias células sanguíneas, entre ellas, discos bicóncavos de $8 \mu$ aproximadamente, con aspecto aterciopelado, embebidos en fibrina (Figura 15).

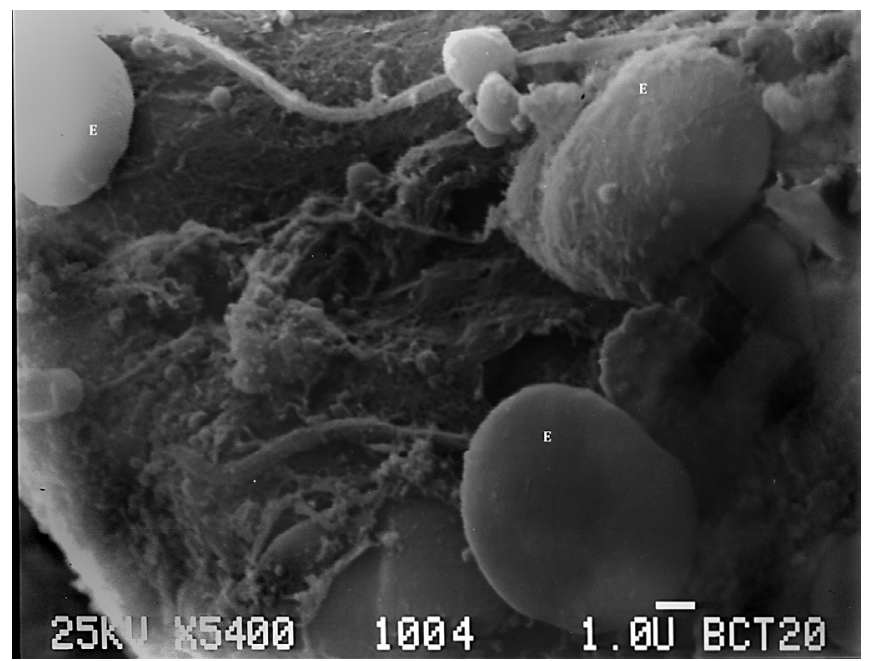

FIGURA 15. Presencia de células sanguíneas, eritrocitos (E) (Fotografía: Silvia Antuna y Luisa Mainou, 2004).

\section{Discusión}

Gracias a diversas condiciones ambientales y microambientales, es común la preservación de células sanguíneas en restos óseos o en tejidos momificados: prueba de ello son los estudios de Martill y Unwin (1997), quie- nes las hallaron, en su investigación por medio de MEB, en huesos de dinosaurios. En éstos se preservaron además osteocitos, según demostraron Higby Schweitzer et al. (2013) por medio de análisis por MEB. En el 2013 Armitage y Anderson estudiaron fósiles de Tricereatops horridus, y encontraron tanto osteocitos como tejido blando mediante la utilización de esta misma técnica analítica (Armitage y Anderson 2013).

Por supuesto, también se han realizado estudios de MEB en restos orgánicos de humanos, entre los cuales destacan el análisis de los restos de Agnés Sorel, una mujer de la élite francesa que murió en 1450; de Luis XI, rey de Francia, y de Carlota de Savoya, su segunda esposa, que reportaron la presencia de células sanguíneas (Charlier et al. 2008).

Sin embargo, pocos son los análisis por medio de MEB realizados a objetos antiguos relacionados con rituales sagrados. Un caso particular es el que llevaron a cabo Mazel y Charlier (2006), autores que investigaron estatuiIlas elaboradas con madera, datadas para antes del siglo XIV d. C., que presentaron una pátina rugosa color café oscuro que, a la observación mediante MEB, reveló la presencia de eritrocitos.

Nuestra INVESTIGACIÓN ha presentado el análisis con MEB de piezas prehispánicas elaboradas y utilizadas por distintas culturas del México prehispánico: punzones de hueso asociados con la cultura maya del periodo Clásico; los tranchets, que pertenecen a la cultura cantonesa; los cuchillos sacrificiales de la cultura xajay de occidente, y la punta de maguey de los otomíes. Todos los objetos se localizaron en distintas áreas de México y estuvieron enterrados o depositados en diversos contextos arqueológicos, como cistas, entierro directo sobre el suelo y dentro de agua helada. A pesar de estas diferencias, los objetos estudiados han conservado en su superficie restos de tejidos orgánicos.

En cuanto a los discos bicóncavos que se reconocieron como eritrocitos, se sabe que son humanos por razón de que su tamaño difiere según la especie de mamíferos de la que proviene la sangre: la medida de los correspondientes a humanos oscila entre las 7 y las $8 \mu$ (Bello 2004:16), mientras que, entre otros, los de especies de perro y cerdo miden $7 \mu$, los de felinos $5.8 \mu$, los de equinos $5.7 \mu$, los de bovinos $5.5 \mu$ y los de caprinos $4 \mu$ (Mondragón y Robles 2007:33-39). No obstante, la hematología y la hemotafonomía indican que los eritrocitos humanos (que son los que se analizaron) pueden cambiar de forma y tamaño tanto por las condiciones del cuerpo humano al que pertenecen como por factores externos (Rudenko 2010; Stasiuk 2009).

Además, se descubrieron restos de fibras de músculo liso, así como de fibrina, colágena y piel que, aunque, por sus características morfológicas no son atribuibles a una especie en particular, sí es válido suponer que son humanos, puesto que acompañan a los eritrocitos $y$, en muchos casos, están adheridos a tales estructuras. 
Si bien cabe señalar que en general los restos orgánicos se conservan mejor en lugares secos, con poca humedad, quedan por explicarse las variables que facultaron la preservación de las células sanguíneas y tejidos corporales diversos de estos objetos en particular, dado que su contexto arqueológico no era ése. En nuestra opinión, el principal factor que ayudó a la conservación de estas estructuras orgánicas fue la desecación y, en el caso de la sangre, su coagulación; no obstante, es posible que otras circunstancias diagenéticas, como su parcial mineralización, hayan favorecido también la conservación de los tejidos orgánicos hallados. Esta hipótesis tendrá que confirmarse mediante futuras investigaciones enfocadas a comprender la formación del contexto arqueológico, particularmente, los procesos de descarte/enterramiento, tomando en cuenta las condiciones edafológicas y climáticas de cada caso para, así, poder realizar las interpretaciones pertinentes.

\section{Conclusiones}

La medicina forense se ha especializado en descubrir, con base en múltiples técnicas, análisis y estudios, la presencia de restos sanguíneos depositados en distintas superficies mediante la tinción de partes de la misma; las sustancias más conocidos son el luminol y BLUESTAR ${ }^{\circledR}$ FORENSIC; sin embargo, existen otras técnicas que utilizan sustancias como el ácido etilendiaminotetraacétiCO (EDTA), la tetrametilbenzidina (TMB) y la fenolftaleína (Mathenson, Hall y Viel 2009:192-193). No obstante, hay dos impedimentos para que tales pruebas se apliquen directamente a objetos que pertenecen a culturas pretéritas:

- La composición molecular, simbolismo y estética se verían comprometidos, puesto que las técnicas utilizadas son invasivas y, en muchos casos, la muestra se destruye para su análisis.

- Gran parte de los componentes de las estructuras biológicas encontradas en estos instrumentos ha sufrido el natural proceso diagenético, lo que los ha mineralizado parcialmente.

Por estas razones, la MEB es la mejor técnica para detectar, identificar y demostrar la presencia de tales restos orgánicos: así empleada, abre un campo nuevo en la conservación del patrimonio cultural y el desarrollo de la interdisciplina con el área de las ciencias biológicas, en especial, con la medicina.

El hecho de haber identificado restos humanos en estos instrumentos rituales comprueba la capacidad tanto de las células sanguíneas como de los tejidos humanos de adherirse a distintas superficies y soportar un sinnúmero de factores de intemperismo y diagenéticos. Nuestros hallazgos proporcionan sustento científico para solidificar una hipótesis elaborada desde diferentes campos epistemológicos —las fuentes etnohistóricas, arqueológi- cas y de antropología física - que sugieren la práctica de sacrificios humanos y autosacrificios en pueblos prehispánicos mesoamericanos. Por esto consideramos que el presente estudio es un aporte importante, ya que son escasos aquellos realizados en instrumentos utilizados en rituales, y menos aún los que reportan la presencia de restos tisulares humanos diferentes de la sangre.

\section{Agradecimientos}

Agradecemos al doctor Ángel García Cook, de la Dirección de Etnología y Antropología Social del Instituto Nacional de Antropología e Historia (DEAS-INAH, México), a la doctora Yadira Martínez Callejas (DEAS-INAH, México), al maestro Roberto García Moll (INAH) y al doctor Luis Morett (Universidad de Chapingo, México) por darnos acceso a los materiales arqueológicos aquí analizados. Asimismo, le debemos gratitud, por su ayuda técnica y la microfotografía, a Gerardo Villa-Sánchez, de la Subdirección de Laboratorios y Apoyo Académico del INAH (SLAA-INAH, México); a Yolanda Hornelas Orozco, del Instituto de Ciencias del Mar y Limnología de la Universidad Nacional Autónoma de México (ICMyL-UNAM, México) y a Armando Zepeda-Rodríguez, del Departamento de Biología Celular y Tisular de la Facultad de Medicina de la UNAM (FacMed-UNAM, México), técnicos especializados en el manejo de los microscopios electrónicos de barrido.

\section{Referencias}

Allen, Jane, Margaret Newman, Mary Riford y Gavin Archer 1995 "Blood and Plant Residues on Hawaiian Stone Tools from Two Archaeological Sites in Upland Kàane'ohe, Ko'olaw Poko District, O'ahu Island", Asian Perspective, 34 (2):283-302.

Anderson, Patricia

1980 "A Testimony of Prehistoric Tasks. Diagnostic Residues on Stone Tool Working Edges", World Archaeology, 12 (2): 181-194.

Armitage, Mark y Kevin Lee Anderson

2013 "Soft Sheets of Fibrillar Bone from a Fossil of the Supraorbital Horn of the Dinosaur Triceratops horridus", Acta Histochemica, 115 (6):603-608.

Barnard, Hans y Jelmer W. Eerkens (eds.) 2007 Theory and Practice of Archaeological Residue Analysis, Londres, British Archaeological Reports.

Bello, Abel 2004 Hematología básica, México, Prado.

Boone, Elizabeth (ed.)

1984 Ritual Human Sacrifice in Mesoamerica, Washington, Dumbarthon Oaks.

Brown, Terry y Keri Brown

2011 "Potential and Problems of Immunological Methods in Biomolecular", en Terry Brown y Keri Brown, Biomolecular Archaeology: an Introduction, Oxford, Wiley-Blackwel, 50 . 
Charlier, P., P. Georges, F. Bouchet, F. Hugnh-Charlier et al. 2008 "The microscopic (optical and SEM) examination of putrefaction fluid deposits (PFD), potential interest in forensic anthropology", Virchows Archiv, 453 (4):377-386.

Dier, Amanda

2011 "Current Approaches to Protein Residue Analysis", Popular Archaeology, 4, documento electrónico disponible en [http://popular-archaeology.com/issue/september-2011/article/current-approaches-to-protein-residue-analysis], consultado en abril de 2016.

Eisele, J. A., D. D. Fowler, G. Haynes y R. A. Lewis 1995 "Survival and Detection of Blood Residues on Stone Tools", Antiquity, 69 (162):36-46.

González, Yólotl

1985 El sacrificio humano entre los mexicas, México, FCE.

\section{Graulich, Michelle}

2005 Les sacrifices humaines chez les aztèques, París, Fayard.

Henderson, Lucía

2012 "Buscando las entrañas: un reconocimiento del sacrificio humano en el mundo maya a partir del periodo Preclásico", en Bárbara Arroyo, Lorena Paiz Aragón y Héctor Mejía (coords.), XXV Simposio de Investigaciones Arqueológicas en Guatemala, Guatemala, Ministerio de Cultura y Deporte, Instituto de Antropología e Historia, Asociación Tikal, 11131132.

Higby Schweitzer, Mary, Recep Avci, Timothy Collier y Mark B. Goodwin

2008 "Microscopic, Chemical and Molecular Methods for Examining Fossil Preservation", Comptes Rendus Palevol, 7 (2-3):159-184.

Higby Schweitzer, Mary, Wenxia Zheng, Timothy P. Cleland y Marshall Bern

2013 "Molecular Analyses of Dinosaur Osteocytes Support the Presence of Endogenous Molecules", Bone, 52 (1):414423.

Hortolà, Policarp

1992 "SEM Analysis of Red Blood Cells in Aged Human Bloodstains", Forensic Science International, 55 (2):139-159. 2002 "Red Blood Cell Haemotaphonomy of Experimental Human Bloodstains on Techno-prehistoric Lithic Raw Materials", Journal of Archaeological Science, 29 (7):733-739.

2004 "The 'Strange' World of Blood Stain Cells, a Brief Overview of Haemotaphonomy", Problems of Forensic Science, 57 (LVII):16-23.

Ibarra García, Laura

2001 "Los sacrificios humanos. Una explicación desde la teoría histórico-genética", Estudios de Cultura Náhuatl, 32: 341-358.

Jones, Peta

2009 "A Microstratigraphic Investigation into the Longevity of Archaeological Residues, Sterkfontein, South Africa", en Michael Haslam, Gail Robertson, Alison Crowther, Sue Nugent y Luke Kirkwood (eds.), Archaeological Science Under a Microscope, Studies in Residues in DNA Analysis in Honor of Thomas H. Loy, Canberra, Australian National University (ANU) Press, 29-46.
Junco, Roberto

2010 "Lagunas del Nevado de Toluca, estado de México. Devoción prehispánica", Arqueología Mexicana, 105:43-47.

Kooyman, P. Brian 2001 Understanding Stone Tools and Archaeological Sites, Albuquerque, U Calgary/UNM.

Kron, Hope 2006 "Human Sacrifice Among the Maya: An Analysis of Patterns in Belize", Totem: The University of Western Ontario Journal of Anthropology, 14 (1):29-45.

Leach, Jeff y Raymond Mauldin

1995 "Additional Comments in Blood Residue and Analysis in Archaeology", Antiquity, 69 (266):1020-1022.

López Austin, Alfredo y Leonardo López Luján

2010 "El sacrificio humano entre los mexicas", Arqueología Mexicana, 103:24-33.

López Luján, Leonardo y Guilhem Olivier (coords.) 2010 El sacrificio humano en la tradición religiosa mesoamericana, México, INAH/IIH-UNAM.

Loy, Thomas $\mathrm{H}$.

1983 "Prehistoric Blood Residues: Detection on Tool Surfaces and Identification of Species of Origin", Science, 220 (4603):1269-1271.

1987 "Recent Advances in Blood Residue and Analysis", en W. R. Ambrose y J. M. J. Mummery (eds.), Archaeometry: Futher Australasian Studies, Canberra, Australian National University (ANU), 57-65.

1993 "The Artifact as Site: An Example of the Biomolecular Analysis of Organic Residues on Prehistoric Tools", World Archaeology, 25 (1):44-63.

1998 "Blood on the Axe", New Scientist, 159 (2151): 40-43.

Loy, Thomas H. y B. L. Hardy

1992 "Blood Residue Analysis on 90000 year old Stone Tools from Tabun Cave, Israel", Antiquity, 66 (250):24-35.

Mainou, Luisa

2009 "Preservando para la posteridad. Bastones de mando y púas de maguey", en Pilar Luna, Arturo Montero y Roberto Junco, Las aguas celestiales: Nevado de Toluca, México, INAH, 134-138.

Mainou, Luisa, Teresa Fortoul y Silvia Antuna

1994 "Evidencias de restos humanos en cuchillos de obsidiana", en Fernando López Aguilar, Proyecto Valle del Mezquital. Informe de la quinta temporada de trabajo de campo, México, ENAH/Centro Regional Hidalgo-Gobierno del Estado de Hidalgo/Conacyt, 66-69.

Malainey, Mary 2011 A Consumer's Guide to Archaeological Science. Analytical Techniques, Nueva York, Springer.

Martill, David y David Unwin 1997 "Small Sphere in Fossil Bones: Blood Corpuscles or Diagenetic Products", Paleontology, 40 (3):619-624.

Martínez Callejas, Yadira en prensa "Función de algunos instrumentos de obsidiana en las ceremonias rituales de Cantona-Puebla".

Matherson, Carney, Jay Hall y Rene Viel 2009 “Drawing First Blood from Maya Ceramics at Copán, 
Honduras", en Michael Haslam, Gail Robertson, Alison Crowther, Sue Nugent y Luke Kirkwood (eds.), Archaeological Science Under a Microscope, Studies in Residues in DNA Analysis in Honor of Thomas H. Loy, Canberra, Australian National University (ANU) Press, 190-197.

Mazel, V., P. Richardin y P. Charlier

2006 "Restes biologiques dans les patines rituelles de la statuaire Dogon (Mali)", en Philippe Charlier (coord.), 1er CoIloque International de Pathographie, Loches, De Boccard, 131-144.

Mondragón Vargas, Rosa Luz y Patricia Robles de la Torre 2007 "Eritrocitos", en Núñez Luis y Jean Bouda (coords.) Patología clínica veterinaria, México, FMVZ-UNAM, 33-39.

Nájera, Martha Ilia

1987 El don de la sangre en el equilibrio cósmico: el sacrificio y el autosacrificio sangriento entre los antiguos mayas, México, Centro de Estudios Mayas-IIFL-UnAM.

Núñez Ochoa, Luis y Jean Bouda 2007 Patología clínica veterinaria, México, FMVZ-UNAM.

Ribeiro Marques, María

2013 "El sacrificio humano entre los mayas: los cenotes de Yucatán como cementerios acuáticos", trabajo de máster en Historia y Antropología de América, Madrid, Facultad de Geografía e Historia-UCM.

Rudenko, Sergey

2010 "Erythrocyte Morphological States, Phases, Transitions and Trajectories", Biochim et Biophys Acta, 1798 (9):17671778.

Sepúlveda Saavedra, Julio 2014 Texto Atlas de Histología. Biología Celular y Tisular, México, McGraw-Hill Interamericana.

Stasiuk, M., G. Kijanka y A. Kozubek

2009 "Transformations of Erythrocytes Shape and its Regulation", Postepy Biochem, 55 (4):425-433.

Stuart, David 2013 "Report: Two Inscribed Bones from Yaxchilan", Maya Decipherment. Ideas on Ancient Maya Writing and Iconography [blog en línea], documento electrónico disponible en [https://decipherment.wordpress.com/2013/05/16/reporttwo-inscribed-bones-from-yaxchilan], consultado en noviembre de 2016.

Tiesler, Vera y Andrea Cucina

2010 "Sacrificio, tratamiento y ofrenda entre los mayas peninsulares", en L. López Luján y G. Olivier (coords.), El sacrificio humano en la tradición religiosa mesoamericana, México, INAH/IIH-UNAM.

\section{Síntesis curricular del/los autor/es}

\section{Luisa Mainou Cervantes}

Coordinación Nacional de Conservación del Patrimonio Cultural (CNCPC),

Instituto Nacional de Antropología e Historia (INAH), México gatomainou@hotmail.com

Licenciada en Restauración por la Escuela Nacional de Conservación, Restauración y Museografía (ENCRYM-INAH) Restaurador perito del INAH. Ganadora, en 1993, del premio Paul Coremans de los premios INAH por la mejor tesis de licenciatura y, en 1994, acreedora a mención honorífica en la misma área por mejor trabajo de investigación. Especialista en conservación y restauración de patrimonio cultural de origen orgánico. Desde hace 28 años realiza investigación sobre el deterioro y tratamientos de conservación por medio de microscopia electrónica de barrido (MEB). Su línea de investigación se centra en el material orgánico y el efecto de la autolisis y la putrefacción del cuerpo sobre los objetos culturales. Ha estudiado gran variedad de piezas pertenecientes a entierros arqueológicos, prehispánicos y coloniales. Mediante el uso de (MEB), ha podido evaluar la diagénesis de diferentes tipos de tejidos (blandos y duros). Con todo ello, ha logrado identificar y diseñar un abordaje tafonómico específico para preservar tejidos óseos y blandos con base en su bioconsolidación y remineralización.

\section{Silvia Antuna Bizarro}

Departamento de Biología Celular y Tisular,

Facultad de Medicina,

Universidad Nacional Autónoma de México (UNAM), México silpolla@hotmail.com

Médico cirujano, técnico académico asociado C de tiempo completo definitivo, en el Departamento de Biología Celular y Tisular Facultad de Medicina de la UNAM. Coautora de 17 artículos nacionales e internacionales. Experta en la preparación de muestras para la observación en microscopía electrónica de transmisión (MET), de barrido (MEB) y EDS (Energy Dispersive X-ray Spectroscopy) con diferentes metodologías. Técnico en microscopia electrónica en el Departamento de Patología del Instituto Nacional de Cancerología. Certificación de técnico en microscopia electrónica en el Instituto Nacional de Pediatría. Técnico en microscopia electrónica de la Facultad de Ingeniería de la Universidad la Salle. Actualmente cursa la maestría en Ciencias Biológicas con orientación en biología experimental en la Facultad de Ciencias de la UNAM. 


\section{Teresa I. Fortoul Van der Goes}

Departamento de Biología Celular y Tisular,

Facultad de Medicina,

Universidad Nacional Autónoma de México (UNAM), México

fortoul@unam.mx

Médico cirujano, neumólogo, con maestría y doctorado en ciencias por la Universidad Nacional Autónoma de México (UNAM). Profesora de carrera de tiempo completo en el Departamento de Biología Celular y Tisular de la Facultad de Medicina de la UNAM.

Sus líneas de investigación están relacionadas con la morfología, en especial con la histología y ultraestructura, además de daños a la salud por inhalación de metales.

\section{Luisa Straulino Mainou}

Coordinación Nacional de Conservación del Patrimonio Cultural

\section{(CNCPC)}

Instituto Nacional de Antropología e Historia (INAH), México

azucarylimon@gmail.com

Licenciada en Restauración de Bienes Muebles por la Escuela Nacional de Conservación, Restauración y Museografía (ENCRYM-INAH). Maestra en Estudios Mesoamericanos por la Facultad de Filosofía y Letras, UNAM. Fue galardonada con la mención honorífica del Premio INAH Paul Coremans en su tesis de licenciatura (2011), así como con la mención honorífica del Premio INAH Alfonso Caso en la de maestría (2016). Durante los años de 2008 a 2010 colaboró en las diferentes temporadas de los proyectos arqueológicos: Proyecto Tlatelolco, Proyecto Río Bec y el Proyecto de Arqueología Urbana. Todos ellos orientados a la conservación arqueológica tanto de vestigios arquitectónicos como de sus acabados y decoración, sobre todo facturados con morteros de cal y roca, así como la restauración de diversas piezas cerámicas. Desde el 2016 está adscrita a la Coordinación Nacional de Conservación del Patrimonio Cultural en el Taller de Materiales Orgánicos.

Postulado/Submited 09.04.2016

Aceptado/Accepted 22.12.2016

Publicado/Published 31.01.2017 